\title{
Desarrollo Rural en el Perú
}

Mg. Enrique Palacios Lozada

Resumen : En las áreas rurales se encuentra la tercera parte de la población nacional y de la población económica activa del país. Población que presentan altos niveles de exclusión, pobreza y pobreza extrema.

Aspectos que de por sí determinan la necesidad de todo gobierno de priorizar el desarrollo rural como parte integrante de una estrategia de desarrollo nacional.

Palabras claves : Desarrollo rural, nueva ruralidad, competitividad territorial, decisión política.

Hace décadas que se viene abordando la temática del desarrollo rural, bajo diferentes enfoques. Hoy se analiza bajo el concepto de nueva ruralidad y competitividad territorial.

Sin embargo es necesario señalar que los problemas estructurales de la sociedad rural siguen vigentes y no han podido ser solucionados por ninguno de los enfoques de desarrollo rural. 


\section{Enrique Palacios Lozada}

Toda noción de desarrollo como lo señala Orlando Plaza, involucra una teoría del cambio social. La interpretación del contenido, los agentes, la discrecionalidad, los instrumentos y los medios para lograr el cambio están directamente relacionados con posiciones ideológicas, es decir, como lograr el cambio hacia donde dirigirlos y a quiénes beneficiar.

El considerar a los gobiernos sin ninguna posición ideológica es una falacia, lo cierto y real es que los gobiernos no han priorizado el desarrollo rural.

El tema del desarrollo es complejo y conceptualmente no existe un consenso sobre su definición. Sin embargo, en términos generales lo que se busca es incrementar el bienestar y los derechos humanos de las poblaciones de un país.

Debe buscarse que este desarrollo sea sustentable, lo que se define como el desarrollo económico que satisface a las necesidades actuales sin comprometer la capacidad de generar los recursos de las generaciones futuras.

La definición de desarrollo rural no escapa a esta complejidad real y conceptual. Sin embargo implica un conocimiento de la forma como esta organizada y se reproduce la sociedad rural, un análisis de las articulaciones económicas, sociales y políticas en el interior de esta sociedad rural y sus vinculaciones con la sociedad nacional y global. El rol que cumple el Estado y las instituciones civiles.

Razón más que suficiente para señalar que el desarrollo rural tiene que estar inscrito en una propuesta de desarrollo del país.

Los diferentes modelos de desarrollo rural han tenido como base el desarrollo agropecuario por lo que ha tenido una conceptualización y aplicación sectorial. Han considerado como base conceptual la modernidad, y el incremento de la producción, productividad y el acercamiento a los mercados; factores necesarios pero no suficientes para explicar el funcionamiento de la sociedad rural y su desarrollo.

El mundo rural es más complejo y diverso que lo agropecuario, pero este sigue 


\section{Desarrollo rural en el Perú}

siendo importante, donde coexisten una multiplicidad de actividades (artesanía, turismo, industria, etc.) articuladas a lo rural.

El sector agrario ha perdido ponderación dentro de la sociedad rural, señalándose que el $51 \%$ de los ingresos provienen de actividades no agrícolas. Sin embargo la agricultura sigue siendo la actividad económica más significativa en la sociedad rural.

Los economistas y estudiosos del desarrollo señalan con toda claridad que país que no resuelva su problema agrario no puede alcanzar el desarrollo. La producción agrícola y la soberanía alimentaria son necesarias para el desarrollo de los pueblos pues de ellas depende el acceso a cantidades suficientes de alimentos. Además es la base alrededor de lo cual se organizan las sociedades rurales.

El desarrollo agrario no sólo es un problema de innovación tecnológica, de inversión, de mercado, de calificación del recurso humano, etc. Sino es un tema de decisión política de quien elabora y ejecuta la estrategia de desarrollo y a quien favorece.

El desarrollo agrícola es parte del desarrollo rural el cual a su vez es parte del desarrollo regional y este del desarrollo nacional, por eso inadecuado e intrascendente pretender realizar un Plan de Desarrollo Rural aislado.

Al medio rural se le caracteriza por su posición declinante en el contexto nacional, donde la condición de vida del habitante rural es de menor calidad y presenta un alto porcentaje de pobreza y de exclusión social.

Por décadas los modelos de desarrollo rural en el Perú como en otros países con población rural significativa, han estado basados en una visión que miraba al sector rural como agrícola, desligándolo de su entorno urbano y de las actividades multisectoriales existentes por lo tanto se le aplicaban políticas de desarrollo agrario. Al campo se le vio como abastecedora de la ciudad y nunca se entendió como podrían establecerse relaciones de intercambio más equitativas entre el campo y la ciudad. 


\section{Enrique Palacios Lozada}

El nuevo paradigma de desarrollo rural está centrado en los conceptos de nueva ruralidad y competitividad territorial.

La nueva ruralidad que consiste en reconocer que lo rural no sólo es lo agrario, sino que coexisten otras actividades como lo artesanal, turístico, industrial, etc. Que permiten generar empleo e ingreso a la población rural.

Lo territorial que reconoce la heterogeneidad del ámbito rural, donde se desarrollan aspectos multifuncionales y de pluriactividades lo que permite proponer estrategias diferenciadas para los distintos territorios.

Enfoque orientado al crecimiento endógeno local, regional y descentralizado; que requiere el acceso y desarrollo de los mercados, así como la accesibilidad de los bienes y servicios públicos.

Enfoque que reconoce que existe una interdependencia entre lo urbano y lo rural que no sólo se refiere a la producción y consumo de alimentos, sino de redes sociales, las comunicaciones, el mercado laboral. Entre otros aspectos.

En las áreas rurales se encuentra la tercera parte de la población nacional y de la población económica Activa del País. Población que presentan altos niveles de exclusión, pobreza ( $75 \%$ ) y pobreza extrema $(50 \%)$ aspectos que de por sí determinan la necesidad de todo gobierno de priorizar el desarrollo rural como parte integrante de una estrategia de desarrollo nacional.

Estrategia que reduzca la pobreza y exclusión rural; donde el crecimiento económico nacional y el entorno macroeconómico favorable son necesarios pero no suficientes para lograr estos objetivos, tal como lo demuestran los hechos reales hoy.

Y donde el proceso de globalización implica una mayor integración de las economías, y que constituye una fuente de oportunidades y desafíos. Pero que implica un debilitamiento del binomio Estado-nación y de la soberanía de las políticas nacionales frente al mercado mundial. Donde existe predominancia de ciertos Estados y de empresas transnacionales que determinan las relaciones existentes que se establecen 


\section{Desarrollo rural en el Perú}

en los mercados mundiales y que influyen en las políticas de desarrollo rural.

Los creadores de enfoques y políticas de desarrollo rural poseen sin duda un conocimiento académico-científico y técnico que el sujeto rural no lo tiene, pero no tiene un conocimiento total de su vida y de su lógica de actuar. Por lo que es necesario establecer una relación igualitaria y participativa entre el sujeto y el objeto de lo que se investiga o quien va a afectar las políticas que se propone.

Existe una insuficiente relación dialéctica entre los enfoques teóricos y la realidad. No es posible considerar a las sociedades rurales y sus espacios como estáticos, son realidades cambiantes, donde el Estado ha cumplido un rol con sus actividades y políticas, las cuales no han favorecido a los más pobres y excluidos y cuyos porcentajes en la sociedad rural tiene niveles significativos.

En resumen el desarrollo rural es un tema de decisión política que tiene que ser abordado dentro de un plan estratégico de desarrollo nacional; donde las leyes, planes y programas por si solos no cambian la realidad. 


\section{BIBLIOGRAFÍA}

1. Desarrollo Rural: Mendieta, Claudia, Agreda, Víctor Cies.

2. Desarrollo Territorial Rural. Schejtman, Alexander. Santiago de Chile.

3. Desarrollo Rural. Plaza, Orlando. PUC.

4. Desarrollo Rural en América Latina y el Caribe CEPAL.

5. Desarrollo Rural. Sancho, José. PARANINFO.

6. Enfoques sobre desarrollo Rural en América Latina, Europa. Kay, Cristóbal.

7. Estrategias y políticas de desarrollo rural. Trivelli, Carolina. Economía, Sociedad CIES.

8. La Nueva Ruralidad en Europa y su interés para América Latina. Pérez,Antonio; Caballero, José María FAO.

9. Nueva Ruralidad y Competitividad Territorial. Eguren, Fernando; Pérez,Edelmira IDEAS.

10. Reforma Agraria y Desarrollo Rural en la región Andina. Eguren, Fernando. CEPES. 